\title{
ASÍ SE LLAMAN LAS MUJERES EN EL TEATRO DE GOLDONI
}

THIS IS THE NAME OF WOMEN IN THE GOLDONI THEATER

Teresa Gil García

Universidad Complutense de Madrid

\section{Resumen:}

En este artículo se estudia el proceso de renovación que el teatro de Carlo Goldoni, uno de los padres de la comedia italiana, sufrió del s.XVIII y la transformación sobre todo sus personajes femeninos, aunque la diferencia entre sexos seguía bien patente en todos los ambientes dejando a la mujer relegada a la cría y educación de los hijos. Se hace un recorrido por el teatro del autor desgranando la construcción de estos personajes y las características atribuidas a cada una de ellas.

\section{Palabras Clave:}

Carlo Goldoni, mujer, comedia italiana, teatro

\section{Abstract:}

This article studies the process of renovation that the theater of Carlo Goldoni, one of the fathers of Italian comedy, underwent in the 18th century and the transformation, especially of its female characters, although the difference between the sexes was still very evident in all of the environments leaving women relegated to raising and educating children. A tour of the author's theater is made, showing the construction of these characters and the characteristics attributed to each one of them.

\section{Keywords:}

Carlo Goldoni, women, italian comedy, theater 
Tutto il mio piacere consiste in vedermi servita, vagheggiata, adorata. Questa è la mia debolezza, e questa è la debolezza di quasi tutte le donne.

(Mirandolina)

En el siglo XVIII, mientras la civilización veneciana se teñía de crepúsculo, Carlo Goldoni preparaba la reforma de su teatro consiguiendo que la expresión de los actores representara efectivamente la cara humana de los hombres y mujeres de su tiempo. Son sobre todo ellas, los personajes femeninos, las que mejor van a demostrar la renovación perseguida por el comediógrafo, y no tanto porque Goldoni no se hubiera aplicado con maestría en la construcción de distintos modelos escénicos de mujer que han pasado a ser proverbiales en la historia del espectáculo, o de la cuestión femenina en general. El verdadero acierto del autor ha sido el de enseñar a los espectadores a mirar la escena de otra manera, de forma que, tras el telón descorrido, pudieran observar ese espacio que la sociedad les ofrecía para vivir su vida y a su manera. Más que sus compañeros de época, las mujeres estaban sometidas al equilibrio entre las fuerzas inestables de la tradición que las quiere conservar en su papel y el impulso renovador que las lleva a asumir otros compromisos.

Por esta vía, los personajes femeninos encuentran en las comedias de Goldoni la mejor elaboración dramática de su historia, pues la visión innovadora que quiere aplicar razonablemente al teatro pasa por eliminar el velo encubridor de la verdadera naturaleza de las cosas: hombres y mujeres son los que son, los que viven en ese mundo, y sólo hay que saber desvelarlos y escribirlos.

Y estamos en el siglo XVIII, cuando las últimas manifestaciones de la sociedad monolítica del Antiguo Régimen dejan paso libre a su transformación en un poliedro de múltiples facetas que en el teatro, como modelo de vida, ofrece ejemplos espectaculares muy distintos a los anteriores. Aquí se mezclan los humanos vicios y virtudes con aires nuevos que fomentan deseos de libertad y democracia. Ahora bien, en el siglo XVIII el término democracia no significaba lo que hoy entendemos como gobierno del pueblo, sino la búsqueda de un mayor equilibrio entre los distintos estamentos de la sociedad, consecuencia de la crítica que ya se hacía de la concentración de poderes en manos de unos pocos (Palmer 1971: 24-32).

Sobre este entramado se construye el universo de Goldoni, creando figuras que son como la vida misma. Su idea del teatro, pues, le permite poner en evidencia y con el efecto de firme anclaje en la realidad, la sociedad a través del tejido espectacular de sus dramas. Sus personajes, y en este caso, sus personajes femeninos, se muestran con tal caracterización y verosimilitud que por ningún otro medio escrito los receptores de ayer y de hoy, podrían haber captado mejor las luces y las sombras de la mentalidad colectiva que distingue el siglo XVIII. Porque precisamente la lucha contra prejuicios y 
residuos irracionales para la creación de un mundo nuevo se advierte especialmente en aquellas manifestaciones en las que el ciudadano es el receptor inmediato- ciudadano anónimo pero, eso sí, acertado y confiado en sus energías y potencialidades- pues cualquier intento de reforma procede de una percepción distinta del mundo, un mundo que siempre debe hacer cuentas con el pasado y valorar, sobre todo, la posibilidad y la capacidad de satisfacer las exigencias fundamentales de quien allí vive en un futuro inmediato.

Entendido así, en pocas palabras, un proceso de renovación conlleva además de un cambio radical en las estructuras sociales, un planteamiento diferente en el tratamiento de las manifestaciones públicas, siendo el teatro precisamente, más que otras expresiones culturales, el lugar y el momento en el que el espectador puede observar los mecanismos escondidos donde arraigar su estilo de vida. El triunfo de Goldoni consiste en haber dado forma a la nueva sensibilidad, a la transformación del gusto, a la transmisión de la nueva ética y estética, partiendo de una realidad concreta que no se le escapa por entre las rendijas de lo irracional. Este es el criterio que preside la invención y la redacción de las tramas. Su idea del teatro apunta a una definición de la escena mediante la presentación de conflictos, sentimientos, pasiones que se materializan en personajes casi reales, diríamos, como si fueran material tangible sobre el que trabajar. En sus textos se percibe la validez de la razón para proponer, con intuición, sutileza y buen gusto al público cansado de convenciones, la lección extraída de la observación directa de la vida donde hombres y mujeres están construyendo el mundo real.

Por tal motivo, ningún esquema predeterminado puede serle útil a Goldoni para tan gran objetivo, porque ya nada es como solía ser. Solo sus dotes de observador inteligente de la realidad son capaces de rehacerla espectáculo en la multiplicidad de tipos humanos que la habitan, en la variedad de situaciones vividas e imaginables. El realismo social de Goldoni tiende así un puente entre el cincuenta por ciento de la sociedad y el otro cincuenta, hombre y mujeres, sin alterar las relaciones de una sensata convivencia. Cabrían, desde luego, otras interpretaciones en las comedias de nuestro autor veneciano, pero apoyamos la lectura de Goldoni no solo en planteamientos teóricos de la crítica especializada, sino en la concepción escénica que interesa a estas representaciones. Los espectáculos del Piccolo Teatro de Milán, por ejemplo, dirigidos por uno de sus míticos directores, Strehler, se centraban siempre en piezas de un realismo social declarado y muy explícito, y este ha sido siempre el modo tradicional de llevar a escena a este autor.

Ahora bien, la diferencia entre ambos sexos, entonces muy desfavorable a las mujeres, se acusa en todos los ambientes, entre la mayoría popular analfabeta, y entre la minoría ilustrada. Ni la revolución científica incipiente ni los cambios ideológicos en marcha 
pueden modificar la consideración emocional e intelectual de la condición femenina, ya que su mejor ornamento social y su misión tradicional es tener hijos y educarlos. En la época incluso podemos ver cómo el teórico de la educación de los individuos conforme a su naturaleza, Jean Jacques Rousseau, marca diferencias considerables entre las pautas educativas de Emilio y de Sofía, para quien prevé una base que el matrimonio debe completar siguiendo los consejos y opinión del marido. De igual modo que estas ideas viven por doquier, ya que responden a consideraciones generalizadas o razonadas incluso, también se percibe la voz contraria de quien cuestiona la lógica de estas opiniones y la necesidad de desmontar las bases de una sociedad a punto ya de desaparecer. Y de ahí que se rechace el principio de inferioridad de las mujeres por causa de su naturaleza imperfecta como un disparate y se defienda, incluso, el principio de la educación para todos los que viven dentro de las paredes del hogar como instrumento transformador del género humano y de mejora de la sociedad.

A las mujeres, más que atender a cuestiones de instrucción, que de poco les servirían pues no se las contempla en una vida pública fuera de su casa, lo educativo implica fundamentalmente la necesidad de formarse un carácter, que siempre es un buen apoyo sobre el que aupar la vida y salvar con garbo las funciones asignadas en la sociedad. Son mujeres, diríamos de mucho carácter -y muy bien caracterizadas en el teatro- para ocupar su puesto. El primero, y más literario, es el de la mujer receptora de cultura. $\mathrm{Y}$ aquí aparece, entre otras, Gasparina, con ese nombre tan evocador de la condición literaria femenina en la ciudad de Venecia, la protagonista burguesa de Il campiello, que representa, aun en su juventud diminuta, a un instruido espectador de comedias; ella misma se muestra orgullosa de su condición excepcional que entiende lo que se desarrolla en escena y es capaz incluso de ofrecer un juicio acertado, motivo que le sirve para aumentar sus méritos ante un futuro marido: "Co vago a una commedia,/ Zubito che l'ho vizta,/ Zo giudicar, ze la zè bona, o trizta;/ E quando la me par cattiva a mi,/ Bizogna certo, che la zia cuzì!" (Il Campiello, acto IV, escena II).

No se puede negar que estas propuestas de cambio, aun limitadas, abren paso por su fuerza y novedad a una forma de pensar distinta que un ambiente receptor favorable puede convertir además en motor de transformación o, al menos, de progreso. Sólo hay que saber encontrar quien maneje adecuadamente las voces de estos razonamientos y los exponga en la plaza pública para que todos los escuchen; en esto consiste la fuerza social del teatro.

Pero no sería del todo justo que solo viéramos en Goldoni a un magnífico traductor de realidades y creador de dramas en los que imita a la naturaleza de las cosas, su reforma del teatro equivale a un proyecto completo y detallado de invención de personajes que se mueven exclusivamente por el poder de la palabra, que es precisamente el instrumento comunicativo entre todos cuando hay que venir al encuentro de las necesidades 
comunes desde las fatigas propias: "Una comunicazione che gli uomini fanno tra loro delle proprie fatiche per riparare alle comuni necessità". ¿Comercio o comunicación? En este caso, esta frase es la definición de comercio, recogida en el original tratado Della moneta de otro ilustrado contemporáneo de Goldoni, Ferdinando Galiani (Galiani 1751). Aun así tanto comercio como conversación son actividades propias del hombre en una cultura en que ambas realidades son sus puntos emergentes: se habla para participar en la sociedad, para ser reconocido como miembro activo de ella, en unas relaciones en las que también las mujeres tiene algo que añadir. Nuestro autor tiene un sentido muy arraigado de la sociabilidad y de los compromisos que deben todos asumir, cosa que tampoco era extraña pues en el siglo XVIII surge la figura del escritor que vive de su propio trabajo, y este oficio se convierte en moneda de cambio entre el creador y quien está dispuesto a pagar por sus servicios. También Goldoni debía buscar el éxito de sus obras para llevar una existencia digna.

La conciencia de este esquema teatral ofrece la posibilidad de contar con una cantidad excepcional de información: si hay que hablar, se hablará de todo. Mejor aún, encima de un escenario, hay que dejar la palabra, que es creadora de sorpresa, a quien no la ha tenido nunca, a las mujeres. Así que la escena se llena de mujeres de todo tipo, clase y condición, italianas y extranjeras, capaces todas ellas de ilusionar a los espectadores que se sientan en una butaca para solaz de su vida rutinaria, que es otra función digna del teatro. Y les pone un nombre que, como luminoso ropaje poético de su alma, las saca del guion y les da cuerpo. Tanta fuerza creativa les ha transmitido Goldoni a estas mujeres que él ha pasado a la historia como un valeroso defensor, incluso, de la condición femenina en un mundo y una época en el que todavía quedaba por conocer el remedio de sus males.

En sus dramas, como documento testimonial de la mentalidad burguesa (Binni 1976), se reconocen los componentes de aquella civilización iluminista que detesta lo que puede comprometer la tranquila y serena convivencia: mentira, hipocresía, vanagloria, falta de respeto o de palabra; y de ahí la antipatía hacia los nobles vacíos y su ocio de parásitos, sentimientos todos que acercan a Goldoni al patriarca del movimiento ilustrado. La admiración que sentía por Voltaire y por sus obras queda reflejada en el homenaje rendido al francés con su comedia La scozzese, que, si bien mantiene el mismo título del original, es una adaptación a los gustos del público veneciano. A pesar de ser una historia desarrollada en tierra extranjera, esto no le impide a Goldoni resaltar en el teatro de su ciudad la figura de un héroe -heroína en este caso, Lindanacuya fuerza no impresiona por su origen noble, sino por ser una simple ciudadana honesta y por tanto digno modelo que seguir, en una sociedad que valora el lenguaje universal de los sentimientos. En sus Memorias Goldoni advierte de su deuda con la obra francesa: “Già si sapeva, che il fondo di essa non era direttamente mio, ma l'arte, 
e le premure impiegatevi per avvicinarla ai nostri usi, e costumi, equivalsero al inerito dell'invenzione" (Memorias, cap. XLVI, tomo II). No hay edición en castellano de la comedia de Goldoni, en cambio, existe una traducción de La escocesa di Carlo Goldoni al sefardí, trabajo estudiado por Patricia Panico (Panico 2003).

Gran éxito de público acompañó a la representación de La scozzese, que superó incluso al de la comedia de los pescadores de Chioggia, Le baruffe chiozzotte, en la última temporada de Goldoni en Venecia antes de su exilio parisino: quince representaciones tuvo en ese Carnaval del año 1761, por solo nueve del drama local (Pignacco 1996: 118-9). Ni autor ni público pudieron mostrar mejor su reconocimiento a la universalidad de las Luces y a la intención Voltaire, que antes había escrito "La comédie intitulée L'Écossaise, nous parut un de ces ouvrages qui peuvent réussir dans toutes les langues parce que l'auteur peint la nature, qui est partout la même" (Voltaire 1768: 176). Goldoni se atrevió a llevar a escena verdades universales, a pesar del temor a las críticas no disimuladas de sus detractores que eran muchos y poderosos. Temían que nuestro veneciano contaminara la tradición con la peste moderna, con el mal francés, que era la Ilustración, escondida en los ropajes de aventuras exóticas y sutiles parlamentos.

Pero diez años antes, en 1750, el mismo año en que desafiaba al público con la creación de dieciséis comedias nuevas, el maestro veneciano ya había explorado las posibilidades de introducir ciertas verdades en otra figura femenina, procedente de la patria inglesa de las Luces (Trivero 1993), la protagonista de la novela de Samuel Richardson, Pamela or Vertue Rewarded, y había conseguido materializar la atención de los espectadores en una comedia titulada en su nombre Pamela nubile -más tarde, vistas las posibilidades escénicas, la historia tuvo su continuación en la Pamela maritata-. La ampliación del espacio dramático con elementos novelescos de gran éxito en Europa, a veces tildados de lacrimosi, en cambio, demuestra la posibilidad efectiva de trasladar a las costumbres y a la moral italianas, categorías de juicio ético válidas para hacer posible la coincidencia entre el bien individual y el de todos, que es aspiración de los reformadores ilustrados. Y sin embargo, los críticos más conservadores y radicales rechazan las innovaciones que intenta llevar a la escena Goldoni. El más radicalizado de ellos, enemigo acérrimo de Volatire, Giuseppe Baretti se atreve incluso a escribir: "Il Goldoni, che in mille luoghi delle sue commedie ha questo difetto, in comune coll' altro poeta Chiari, di voler fare il filosofo e il moralista senza avere studiata nè la morale nè la filosofia, e che, come il Chiari, non distingue mai netto tra il bene e il male, vorrebbe qui distogliere le fanciulle dal pigliar marito" (Baretti 1831: 41).

El juicio de Baretti es excesivo, pues a través de estos personajes femeninos de nombre exótico y extraño a la realidad local, Pamela o Lindana, solo se invita a los espectadores a pensar en que mujeres con estos atributos son dignas de respeto y amor, 
pudiendo por ellas mismas manejar sentimientos. Cierto es que no son ni venecianas ni siquiera italianas, pero aparecen en escena con el carácter simbólico de la feminidad que exige ya el reconocimiento de sus propios designios. Y esto podía alcanzar incluso a ámbitos en los que la tradición defiende otra respuesta. La trama de las comedias deja entrever la posibilidad de matrimonios desiguales (Plebani 2003), cuya razón no es precisamente el acomodo vital que justifica estos compromisos. En esta sociedad burguesa cada vez más perfilada, los condicionamientos familiares y los motivos sociales empezaban a jugar la partida con los sentimientos; y todo por obra y gracia de la razón, que convenía aplicar a lo contingente y a lo importante de la vida, que con estos beneficios y otras mejoras se ampliaba en felicidad y años.

La sintonía entre Goldoni y los ilustrados quedaba expresada en los juicios de los teóricos y defensores de este movimiento intelectual. Voltaire lo elogiaba en sus cartas y el italiano Pietro Verri reconocía un fondo de "virtù vera, d'umanità, di benevolenza, d'amor del dovere" en sus comedias (Verri 1755). Estas palabras más que amables demuestran el respeto de sus contemporáneos hacia quien buscaba también una ética burguesa desde el teatro. Allí, en las tablas de un escenario, los espectadores del siglo XVIII veneciano se topan con discursos que les hacen reflexionar sobre realidades universales y sobre la suya propia, a través de personajes sacados de una aventura emprendida para adoptar usos y costumbres que mejor convienen por coyuntura temporal.

Los nombres extranjeros de las protagonistas de estas dos comedias contienen el punto de exotismo justo para advertir de un comportamiento razonable y una conducta útil a los ciudadanos de la República, que conviene observar aun viniendo del otro lado de los Alpes. Y sin embargo, como hacedor de títulos no daría la impresión de que se hubiera aplicado mucho Goldoni en hacer avanzar el género, pero titular es también un arte y hacerlo bien, propio de artistas. En este caso, un gentilicio, la escocesa Lindana y un nombre propio, Pamela, salvan la exigencia de orientar a los destinatarios del espectáculo. Los títulos de nuestro autor son siempre obras de entendimiento que anuncian a los espectadores lo que se va a tratar o quién va a aparecer en escena, y si con ello les convence de que allí pueden encontrar cosas interesantes, el resultado es siempre un acierto. Y aunque nunca seremos capaces de saber con certeza cuál puede ser la influencia de un buen título en la recepción de un texto, podemos intuir que no es un factor secundario tampoco: unas veces viene antes de lo escrito, otras después; otras, los dueños son los receptores; pero no es imposible entender que esas pocas palabras condensan cierta aura del imaginario del autor. Precisamente, de la interpretación de Franco Fido de los títulos de las comedias de Goldoni, se han percibido detalles muy interesantes para reconstruir la poética que subyace en las comedias del autor veneciano (Fido 1995: 13-21). 
Para tener éxito con una comedia, decía en sus Memorias Goldoni, había que comenzar por convencer a las mujeres, y esto es siempre un buen motivo para esmerarse en lo primero que se lee. En su autobiografía, el autor defiende también que la materia de su teatro proviene de la observación y la reflexión sobre lo que ha visto, y esto no solo le sirve de inspiración, sino que pertenece a su propia naturaleza. Su virtud, su capacidad de atreverse con la pintura de la condición femenina en este caso, consiste en ver la vida también como un teatro. Incluso su otra vocación, la de abogado que defiende a un encausado encierra también un cierto tono espectacular, pues, como si desempeñara un papel, el letrado siempre debe hacer convincentes sus argumentos ante el tribunal para captar benevolencia y justicia. Así también los títulos, en su valor de síntesis, catalogan escuetamente la condición del personaje -culpable o inocente, virtuosa o no- con el fin de guiar a los espectadores. El título marca además el comienzo del espectáculo haciendo que el público se muestre expectante ante lo que se fragua en la escena, y señala el final, al clarificar el sentido de la obra. Constituye, pues un elemento aclaratorio del drama, y desempeña un papel importante al condicionar la asistencia al espectáculo.

Si ya encontramos indicios de la intencionalidad del autor en los títulos de las comedias, no es difícil comprender la abundancia de textos dedicados a las mujeres, donde ellas son además protagonistas, ni tampoco advertir que hay rasgos de cierto feminismo en el tratamiento de estos personajes. Son muchas y de mucha categoría, a pesar del respeto que demuestra Goldoni en la distribución de los papeles escénicos entre hombres y mujeres y el reconocimiento de la superioridad masculina en estas relaciones. No obstante, desde la titulación se capta que a las mujeres las contempla tanto en sus virtudes como en sus defectos, y por tales afectos se atreve a llamar la atención y a alimentar las expectativas del público presentándolas bajo una calificación conveniente a su categoría de común mortal: La donna bizzarra, La donna di garbo, La donna di governo, La donna di maneggio, La donna forte, La donna sola, La donna stravagante, La donna di testa debole, La donna vendicativa, La donna volubile. Incluso más que una donna, una vez es una dama: La dama prudente.

Con mayor o menor fortuna en las tablas, las mujeres de estas comedias muestran en escena la fuerza de su especie a manera de modelo que observar, si bien la contención en la pintura de los caracteres femeninos es acto reflejo del débil equilibrio existente entonces entre el valor atribuido a la mujer en una sociedad todavía misógina y la apertura de miras de la incipiente burguesía. La solución espectacular de los conflictos pasa siempre por mostrar al receptor la eterna lucha entre el bien y lo razonable y los comportamientos ambiguos que hacen pagar un alto precio a quien los sigue. Si hay varias protagonistas, el plural del título muestra con mayor claridad el carácter del grupo femenino que dramatiza Goldoni y esta mentalidad de la época que califica su 
estatus. Aquí encontramos Le donne curiose, Le donne de casa soa, Le donne di buon umore; Le donne gelose, Le donne vendicate (también conocidas como Le contadine bizzarre), convertida en un intermezzo musicale por Niccolò Piccinni y por ello drama jocoso muy famoso en la Europa de su tiempo; incluso existe una traducción al español del año 1763, Las mujeres vengadoras, lo que prueba también la acogida magnífica y rápida de la obra de Goldoni en la España de su tiempo (Pagán 2003). Cuando quiere Goldoni cambia incluso el nombre de la sustancia humana que le sirve de soporte al adjetivo que inspira la pasión, y las convierte en femmine, Le femmine puntigliose.

Ya por el título, los espectadores son capaces de reconstruir en su fantasía la referencia externa que les genera cierto efecto de sentido de la realidad, que es precisamente a lo que aspiraba su autor. Las mujeres que imagina Goldoni, las que traza con palabras elocuentes, son el fundamento de cualidades y defectos percibidos con la intensidad necesaria para que ser como son, como aparecen en escena. Todas van calificadas con epítetos que son modelos de moralismo clásico, centrados en la virtud o en el defecto dominante de la protagonista. Al espectador le toca descubrirlo porque la ironía es también otro de los motores creativos de un título. No se engañe quien asiste a una representación de Le donne di casa soa, pues la siora Bette y la siora Anzola, ceden a la espontánea suposición de imaginarlas sólo como casalinghe, y son mujeres, en cambio, muy resueltas: "Se no fussimo nu che fussimo valente, l'omeni de casa no i xe boni da gente" (Le donne di casa soa, acto I, escena II)

La realidad es que especialmente entre las figuras que representan a la burguesía, como debía ser en la vida, Goldoni coloca personajes provistos de temperamento, autoridad e iniciativa. En el siglo XVIII, Venecia es lugar de destacada presencia femenina en el mundo de las letras, sobre todo porque al cambiar los tiempos, también había medios para que ellas dejaran su huella en la memoria. Hay actrices como Teresa Ventura, casada con el noble Venier, cuya casa se constituyó en un lugar de encuentro para artistas y literatos; damas nobles como Fiorenza Vendramin, hija del propietario del Teatro di San Luca donde estrenaba Goldoni; e incluso estudiosas: Elisabetta Caminer casada con el botánico Antonio Turra, que dirigió un periódico, Il Giornale Enciclopedico donde aparecían noticias, novedades literarias y científicas y se distribuía en toda Europa; y Luisa Bergalli Gozzi esposa de Gasparo y cuñada de Carlo que publicó la primera antología femenina de poesías en dos volúmenes que contienen la obra de más de doscientas poetisas del siglo XIII hasta entonces. Y ellas no debían de ser desconocidas a nuestro veneciano.

Pero hay otra la lista en sus comedias también advierte de los excesos que la mujer puede cometer y el tributo que puede pagar si se excede en sus ambiciones. Como correctivo de la fuerza del carácter femenino más libre e independiente, otro grupo de obras presentan a las protagonistas en el centro de la vida familiar. Ellas son, o 
deben ser -como se ve en La buona madre, La buona moglie, La madre amorosa, La moglie saggia, La sposa sagace, La figlia obbediente, La pupilla-, las defensoras de la familia apreciada como un valor burgués donde se fragua el origen y el remedio de ciertos males que preocupan a todos, y por tanto esta institución es el centro temático de la reforma goldoniana. El nuevo estilo de vida familiar en el siglo XVIII crea las condiciones favorables para el desarrollo de personalidades seguras de sus posibilidades y representa la contribución más importante a las necesidades de la sociedad mercantil. No es difícil enumerar las características de este sistema, aun en su grado de mayor generalización, donde la mujer era l'angelo del focolare, en una expresión que parece ser de acuñación contemporánea a Goldoni. La misión milagrosa de la madre se concreta en su tarea educativa ejemplarizante, lo que aumenta su responsabilidad y el vínculo afectivo con los hijos, creando a veces una continua tensión en la familia, pues esta excesiva importancia de la relación entre madre e hijos no contribuye a una convivencia siempre serena. Y si no, véase como Goldoni no quiere concluir bien La familia del anticuario o la suegra y la nuera, donde un hijo respetuoso se encuentra entre estos dos fuegos femeninos, porque no imagina una solución definitiva al problema: "ma chi può assicurare che queste due dame ristrose non rinnovassero nel giorno appresso le lor contese? Posso ingannarmi, ma il mio sviluppo parmi piú naturale" (Memorias cap.VIII, tomo II). Y luego nos explicó también que tuvo que modificar el título original, El anticuario, al suponer que éste sería un tanto opaco pues el público recordaría más los contrastes dialécticos entre Isabella y Doralice, suegra y nuera, que son precisamente asuntos de envergadura.

Goldoni, con gran sensibilidad, puede imaginar "mujeres razonables" y "madres cariñosas" y cuando no lo son, surge el conflicto. Su idea de educación que genera el equilibrio en la vida burguesa nos lleva a entenderla como una dualidad dialéctica cuyos polos son, de una parte, la norma de la razón y de la otra, la sensibilidad y el amor, y así lo advierte a sus lectores (La buona madre, L'autore a chi legge): "Io ho sempre compatito, e compianto la gioventù mal condotta dall'inclinazione, o dal mal esempio [...]. Non ho mai però compatito, anzi ho sempre detestato, e aborrito i genitori disattenti verso de' loro figliuoli, e specialmente le madri che per soverchio amore tradiscono la loro prole..." El juicio de Goldoni conviene en esta comedia en dialecto veneciano a las desventuras de Nicoletto, sufridor de los manejos de su progenitora, Bárbara, cuyo nombre informa ya de su carácter. No obstante, son los personajes masculinos los que tutelan o deben tutelar al resto de la familia, pues ellas no desempeñan un papel todavía real en esta microsociedad, por mucho que lo intenten. Y por este motivo también encontramos dos comedias interesantes donde las protagonistas son viudas. En La vedova spiritosa, Placida -cuyo nombre advierte irónicamente de un rasgo característico- no parecía en principio dispuesta a renunciar a la libertad que le ofrecía su estado: “La libertà acquistata vo'conservar, 
s'io posso" (La vedova spiritosa, acto I, escena I); en cambio, en La vedova scaltra, Rosaura, tras la muerte de un marido anciano, decide buscar quien colme los deseos de su corazón, con una intuición que combina sentimiento y razón y la guía en sus designios: al pretendiente español lo rechaza, pues quería pasarse por lo que no era, como había hecho Lucrecia, la culta condesa lombarda de La fingida Arcadia frente el exhibicionismo de títulos de su pretendiente italiano (Croce 1963: 99)

Así que, además de que no faltan motivos literarios de la tradición europea, en sus comedias, Goldoni observa las costumbres convencionales que son la base del nuevo orden social, y siempre traza un modelo de comportamiento que no prescinde del respeto a la persona.

Llama la atención que frente a la abundancia de comedias donde se analiza de todo punto de vista la realidad familiar, enfocándola precisamente desde la perspectiva femenina que muestra una visión distinta a la costumbre, hay un número escaso cuya trama da cuenta de los oficios a que éstas se dedican, a pesar de que el trabajo de las mujeres siempre ha sido una fuerza motriz en el desarrollo de la comunidad desde antiguas civilizaciones. Con la esperanza de una tarde de fiesta y de una vida mejor, sobreviven a la rutina que las aplasta Le massere. Son cuatro criadas, Zanetta, Meneghina, Gnese, y donna Rosega, las que filtran en sus parlamentos el complejo y contradictorio mundo de los burgueses venecianos a quienes sirven. $Y$ lo expresan en dialecto, que es el mejor modo de reivindicar la dignidad que les corresponde, al menos hasta donde la fantasía alcanza. En otras dos comedias, La serva amorosa y La cameriera brillante -Argentina se llama precisamente la protagonista porque brilla por sus dotes teatrales y maneja ella sola las situaciones- se hace realidad la criadita resuelta de temperamento vivo y despierto con que se quiere distinguir a la mujer en el siglo XVIII.

Y entre los textos de Goldoni en que una mujer trabaja y lucha para conseguir el reconocimiento y la dignidad, al menos donde la fantasía lo hace posible, encontramos la famosa Locandiera. De los innumerables personajes goldonianos, asociados a un carácter con gracia, humorismo, ingenio y buen gusto, ha quedado en la memoria proverbial la protagonista de esta historia, por su nombre propio. La locandiera es Mirandolina o mejor, Mirand olina es La locandiera, al haberse convertido en el epónimo de libertad femenina; cabe añadir que en los años setenta en España se representaba una adaptación musical del texto que llevaba por título casi un verso: Mirandolina en su posada hace lo que le da la gana. Quizá no sea la obra más significativa de Goldoni, pero es, según sus palabras, la "più morale, la più utile e la più istruttiva". Con el tiempo sería también una de las más representadas y mejor acogida por el público. Ella más que otros personajes representa a la mujer que no desea riquezas ni títulos nobiliarios si no ser respetada por sí misma y merecer el reconocimiento social de 
sus propios méritos: "La nobilità non fa per me. La ricchezza la stimo e non la stimo. Tutto il mio piacere consiste nel vedermi servita, vagheggiata, adorata. Questa è la mia debolezza, e questa è la debolezza di quasi tutte le donne" (La locandiera, acto I, escena IX) . Por otra parte, la historia de una mujer que rechaza a todos sus pretendientes nobles para contentarse con Fabrizio, un pequeño burgués, es una alusión muy directa a la nueva situación social, a un mundo donde han cambiado de tono las relaciones entre todos, nobles y burgueses, mujeres y hombres. Son otros tiempos y por tanto otras costumbres.

Dar vida a personajes supone inventarles un nombre que les conduzca a la eternidad. El nombre, como seña de identidad, es fundamental en el teatro, pues califica y da corporeidad a un personaje vertebrado en torno a una idea. Claro está que por mucho que veamos a los personajes como seres vivos, tampoco podemos obviar que son creaciones de su autor, y de un autor teatral que además se propone entretener y divertir. Mirandolina es un diminutivo que paradójicamente no conviene al espíritu de la protagonista, pues bajo apelativos cariñosos de este tipo se solía presentar en escena a la servetta de la Commedia dell'Arte. Ella, al contrario, dueña de su negocio y de su propia vida, es una mujer fuerte y decidida, cualidades que la han convertido en uno de los primeros retratos femeninos modernos que el teatro nos ha dado.

Y diminuto parece también el nombre de Marcolina, en escena la nuera de Sior Todero Brontolon y mujer de su hijo Pellegrin, aunque bajo esta apariencia nominal divertida y despreocupada, se encierra un cierto Marco de los antiguos romanos, que advierte de un carácter educado para ser fuerte en sus designios. Más que razonable, el personaje antagonista de Sior Todero es una madre de familia, aguerrida, viril casi, que debe responder a las exigencias y las imposiciones de la ideología burguesa, sin más contemplaciones que el respeto y amor por todos los miembros.

Goldoni utiliza para la denominación de las mujeres que salen a escena una onomástica que encierra un mensaje, cuyo significado no plantea más dificultad al auditorio que fijarse en la categoría del personaje y entender el porqué de esta atribución. Los intérpretes de la clase burguesa se materializan en signos de la tradición teatral y narrativa, o relacionados con rasgos de su carácter o costumbres, tal vez escondidos en la etimología de la palabra: Eugenia, Flaminia y Clorinda son las celosas protagonistas de Gli innamorati, donde todo acaba bien porque así debe ser; Giacinta, Costanza, Sabina son las mujeres que en La trilogia della villeggiatura muestran los enfrentamientos, contrastes y desacuerdos que emergen en la dinámica de la vida social.

Fuera de las denominaciones a que Goldoni nos ha acostumbrado para honrar el espíritu femenino, han quedado sin embargo, los trazos más generosos de su expresión. Y sólo el género gramatical del sintagma titular de la comedia nos advierte de que por 
entre las escenas viven eternamente mujeres del pueblo merecedoras también ellas del reconocimiento y del homenaje de los espectadores. Le baruffe chiozzotte no parece un título muy claro para una comedia pues no es la presentación que suele hacer el comediógrafo veneciano de un drama. Aquí la sustancia humana es sustituida por un conflicto, la baruffa, que se personifica en una realidad geográfica y en sus habitantes, haciendo de ellos el paradigma de cuanto puede ocurrir en la vida cotidiana del pueblo. Es una trifulca chiozzotta, pero podía ser una trifulca popular, o incluso una trifulca humana, pues son los sentimientos de todos los que se llevan a escena. Los personajes femeninos de este drama están bautizados con nombres propios de la onomástica popular, de vírgenes milagrosas, o santas patronas protectoras de oficios y devotos. Y a todas ellas se les aplican además las ingeniosas deformaciones nominales que la creatividad lingüística permite a los hablantes: Pasqua, Libera, Checca - hipocorístico de Francesca-, Orsetta -diminutivo de Orsolina- y Lucietta son los nombres de las figuras femeninas de Le baruffe chiozzotte, nombres que se repiten en otras comedias escritas también en dialecto veneciano como Il campiello e I rusteghi. Las mujeres son además gratificadas con esta categoría de apelaciones que descubren rasgos de su carácter: Lucietta, por esa ejemplar referencia a la luz, aparece distinguida como la más abierta de las muchachas, la más avispada, la que irradia más atracción entre los jóvenes de su edad.

Estas virtudes onomásticas se potencian cuando Goldoni crea para los personajes populares un apodo, como ocurre entre la gente del pueblo. La preferencia por el uso de sustantivos que sustituyen al nombre propio está dictada por la costumbre, por la rutina de valorar la dignidad de los convecinos, que unas veces se rebaja, otras es una manifestación del afecto colectivo; pero esta actitud siempre es fruto de la reiteración de un sentimiento que depende del grado de simpatía demostrado a quien se lo merece. Y así lo transmite Goldoni, porque cierto es que en el texto conservan toda su eficacia dramática por su carácter directo y su clara expresividad. De su nombre y su apodo, el espectador advierte una forma de ser del personaje, siendo así capaz de percibir más información en este tratamiento simbólico de la personalidad. Lucietta es, además de la luz en su grupo de amigas, panchiana, esto es fabuladora, fantástica, que cuenta mentiras enmascarando la realidad. Y no sabemos por qué. Cabe preguntarnos si en la mente de Goldoni, la efectividad de los nombres fue concebida sólo para presentarlos y para que los conozcamos mejor. O para que juguemos a divertirnos adivinando su historia. Poesía y verdad son, pues, los ejes justificativos de sus creaciones.

Parece que durante siglos el carácter femenino no ha conocido muchos cambios. Las mujeres son sujeto u objeto de amor, débiles o independientes, felices o infelices, virtuosas o menos. Estos esbozos de sociedad que se mueve por entre las escenas, muestran de qué manera Goldoni saca lección vital del mundo, reconociendo su deuda 
en una expresión ya clásica y conocida de todos: "I due libri su'quali ho più meditato, e di cui non mi pentirò mai di essermi servito, furono il Mondo e il Teatro". Esta es la declaración de principios que proclama con toda lucidez desde la primera edición de sus comedias en 1750, la famosa Bettinelli. Sus textos dramáticos no se inspiran ni en poéticas ni modelos escritos, sino en la realidad de todos. La finalidad era crear una ficción compatible con la vida y destinada a conseguir el objetivo esencial, el respeto del público, que es a la vez, inspirador y destinatario, espectador y protagonista. Y ya que las mujeres constituyen la mitad de los asistentes a las funciones teatrales, a ellas las recompensa con la imaginación de una vida, que es siempre un buen camino para atreverse y aventurarse por mejores y mayores compromisos.

\section{REFERENCIAS BIBLIOGRÁFICAS}

Todas las obras mencionadas de Carlo Goldoni se pueden consultar en ediciones electrónicas:

www.liberliber.it; http://www.intratext.com/IXT/ITA1289/_INDEX.HTM

Las Memorias, también se pueden leer en el original francés en e-book, que se descarga del archivo Google.

Baretti, Giuseppe, “Delle commedie di Carlo Goldoni, avvocato veneto", La frusta letteraria, v. I, 1831, Milano: Bettoni. También en ed. electrónica:

http://www.classicitaliani.it/sette/Baretti_goldoni1.pdf

Binni, Walter, "La misura humana del Goldoni", en Classicismo e neoclasicismo nella letteratura italiana del Settecento, Firenze: La nuova Italia, 1976.

Croce, Alda, "Tirso de Molina e Italia”, Bulletin hispanique, nº 65, 1-2, 1963.

Fido, Franco, "I titoli delle commedie" en Le inquietudini di Goldoni. Saggi e letture, Genova: Costa \& Nolan, 1995.

Galiani, Ferinando, Della moneta, ed. electrónica:

http://socserv2.mcmaster.ca/ econ/ugcm/31l3/galiani/monet2.html

Pagán, Víctor, El teatro de Goldoni en España : comedias y dramas con música entre los siglos dieciocho y veinte. E-print UCM.

Palmer, R.R., L'era delle rivoluzioni democratiche, Milano: Rizzoli, 1971.

Panico, Patrizia, “La escocesa”, Artifara, n. 3, (luglio - dicembre 2003). También en edición digital:

http://www.artifara.com/rivista3/testi/sefardita2.asp.

Pignacco, M. L. “Squarzo degli utili del Teatro (di San Luca) per le recite relative degli Autunni e Carnovali 1758-1770" en C. Alberti e G. Herry, Tra libro e scena, Carlo Goldoni, Venezia: Il Cardo Ed. 1996, pp. 118-9. 
Plebani, T. "Ragion di stato e sentimenti nel Settecento", Storia di Venezia, 2003. Revista electrónica:

http://www.storiadivenezia.net/sito/donne/Plebani_Ragione.pdf

Rousseau, Jean Jacques, Emile. El texto también se puede encontrar en edición digital: http://www.iep.utm.edu/rousseau/

Trivero, P., Goldoni et l'Angleterre", Revue de littérature comparée, III, 1993.

Verri, Pietro, "La vera Commedia, al chiarissimo sig. avv. Carlo Goldoni”, Il Caffé. Texto íntegro en edición electrónica:

http://www.archive.org/stream/delcaffperiodi00ferr/delcaffperiodi00ferr_djvu.txt

Voltaire, Collection complette des œuvres de Mr. de Voltaire, Geneve, Besancele cadet de Carcassonne, 1768. 